JCPDS-International Centre for Diffraction Data

12 Campus Blvd.

Newtown Square, PA 19073-327

\title{
Publishing Agreement
}

1. It is our custom to request authors to vest the worldwide copyright of their papers with the JCPDSInternational Centre for Diffraction Data for the full term of copyright and we would be grateful if you would confirm your acceptance of these terms by signing and returning the agreement below. We will not withhold permission for any reasonable request from you to publish any part of this paper in connection with any other work by you, provided the usual acknowledgements are given regarding copyright notice and reference to the original publication.

2. If it is appropriate, the author's employer may sign this agreement, and in any event the employer may reserve the right to use the paper internally or for promotional purposes only, by so indicating on this agreement. It is understood that proprietary rights other than copyright (including patent rights) are reserved.

3. If the author is a U.S. Government employee and this work was done in that capacity the assignment applies only to the extent allowable by U. S. law. If at least one co-author is not a government employee, said author should sign the agreement.

4. If the author is an employee of the British Government then HMSO will grant a non-exclusive license to publish this paper in the Journal in any form or media provided British crown copyright and user rights (including patent rights) are reserved.

5. The author warrants that the manuscript is the author's original work, and has not been published before. (If excerpts from copyrighted works are included, the author will obtain written permission from the copyright owners and show credit to the sources in the manuscript.) The author also warrants that the article contains no libelous or unlawful statements, and does not infringe on the rights of others.

6. If the work was prepared jointly the author agrees to inform co-authors of the terms of the agreement, and to sign on their behalf.

With the qualifications listed above I assign to JCPDS-International Centre for Diffraction Data, the copyright of my paper entitled

for publication in Powder Diffraction.

If the paper is rejected, this assignment is null and void. 


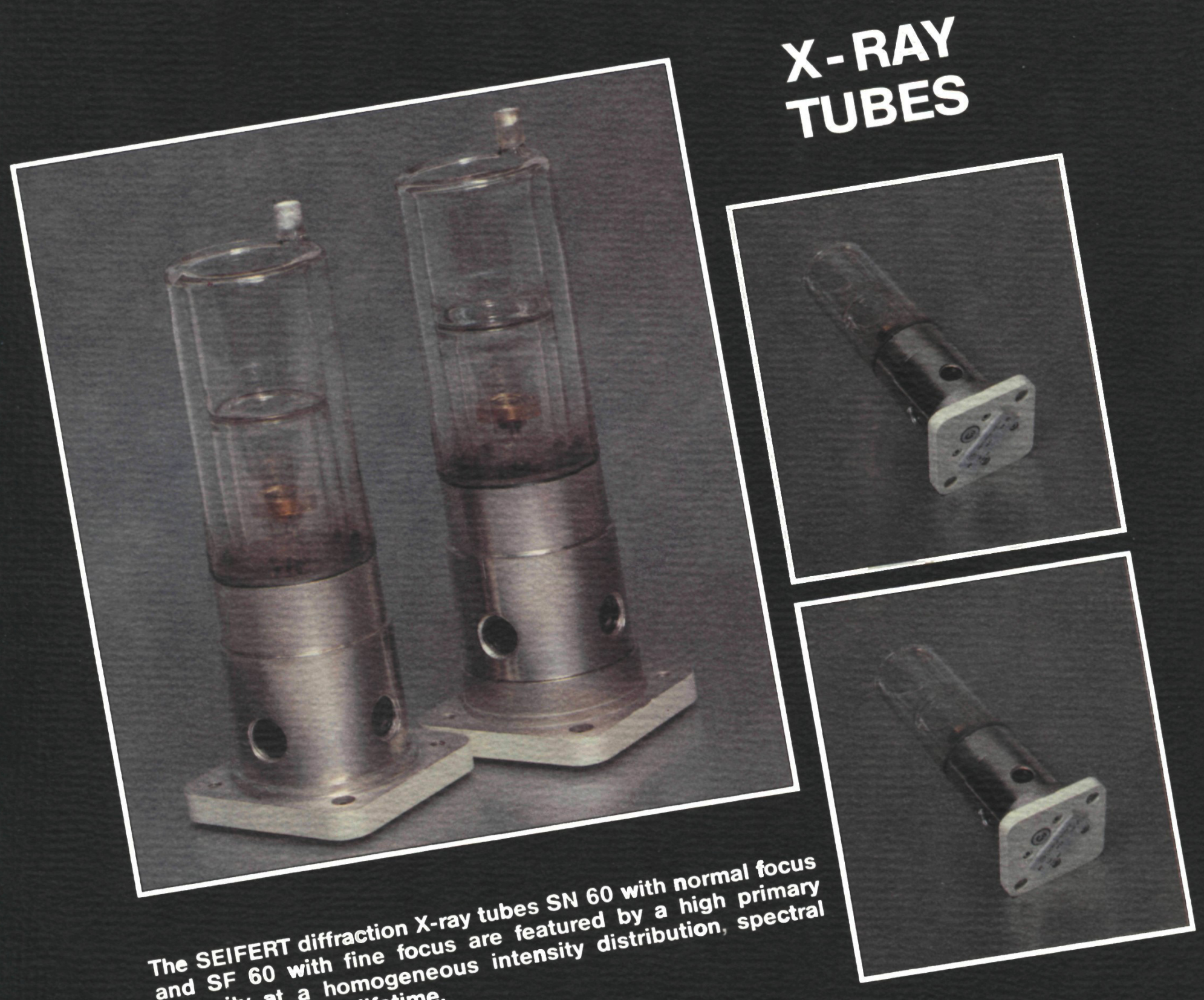
featured by a hion, spectra intensity at a hong lifetime. purity, and

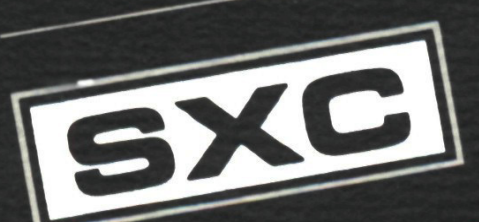

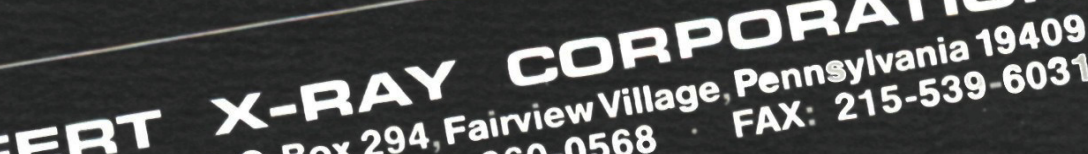
EEIFEF Lane,P.0.Box 294,Fair TWX: 510-660-0568 
$\begin{array}{lllllll}S & C & I & N & T & A & G\end{array}$

\section{The Seintag Pelier X-ray \\ Detector: The Nlaw Indistry \\ Stantard in X-ray ofifiraction}

\section{Another first from Scintag!}

Scintag's exclusive second-generation Peltier-cooled $\mathrm{x}$-ray detector for powder diffractometers is a breakthrough in $x$-ray diffraction. Without the need for liquid nitrogen cooling, Scintag's new detector provides all of the benefits of a solid state detector and more:

\section{- Better sensitivity}

\section{- Superior peak-to-background ratios}

- No alignment required

- No routine maintenance required

For the latest innovations in powder diffraction, Scintag is the clear choice. Contact us today for our brochure and a complete system demonstration, and judge for yourself.

SCINTAG, Inc.

707 Kifer Road • Sunnyvale, CA 94086 USA

Tel. (408) 737-7200 • Fax (408) 737-9841 